\title{
Insights provided by the study of the small intestine in the child and the foetus
}

\author{
JOHN WALKER-SMITH AND THOMAS MACDONALD
}

In May 1962 the CIBA Foundation arranged a study group on 'Intestinal biopsy' in Madrid, which was subsequently published. 'This publication contained a notable paper entitled 'Dissecting microscope appearances of intestinal mucosa' by $\mathrm{C}^{\circ} \mathrm{C}$ Booth and his colleagues at Hammersmith Hospital.' One of us (JW-S) had the good fortune that year to come to the Hammersmith course from Australia, and became fascinated by the three dimensional appearances of the small intestinal mucosa as shown by the dissecting microscope. He became house physician to $\mathrm{C} \mathrm{C}$ Booth in 1963, and as a direct result of this he subsequently embarked upon a career in gastroenterology. He later moved from adult gastroenterology to paediatric gastroenterology at the Royal Alexandra Hospital for Children in Sydney, and applied Booth's descriptive approach to the gross morphology of the small intestinal mucosa in infants and young children. These studies confirmed Booth's observations that examination of small intestinal biopsies with the dissecting microscope greatly facilitated orientation of biopsy specimens in readiness for sectioning, and also that use of this technique permitted rapid diagnosis of a flat small intestinal mucosa.

These studies also extended his observations by establishing in early childhood that the broader villi described by Booth et al as 'leaf-like' were more common than the 'finger-like' villi considered to be normal in the small intestine of adults. Booth and colleagues' had recognised 'finger-like' villi to be the characteristic appearance found in the jejunum of normal healthy adults (Figs. 1,2). This finding of broader villi in children was further investigated in autopsy studies of children in Sydney. ${ }^{4}$ Ferguson and colleagues ${ }^{5}$ had already used the dissecting microscope to study the morphology of 11 stillborn infants dying within four days of birth. They had found that the jejunal villous pattern was mainly finger-like in infants up to 26 weeks gestation. From 26 weeks onwards, however, a preponderance of broader villi described as leaf-like and tongue-like were found.

The technique of Creamer and Leppard ${ }^{t}$ was used to study postmortem bowel. "This takes advantage of the rapid autolysis of the surface epithelium of the small bowel at death, in order to reveal the three dimensional architecture of the connective tissue cores of the villi and also ridged or flat mucosa. The shape of the villous cores at different ages and along the small intestine was studied in a total of 116 children. Sixty one of the children had had no clinical evidence, or at necropsy no pathological evidence, of gastroenterological disease. Fifty five had evidence of gastrointestinal disease.

Booth's observations of the role of dissecting microscopy were extended by the demonstration in these autopsy studies that mucosal abnormalities may not be uniform in the proximal small intestine. A good example of such patchiness of mucosal abnormality was provided by gastroenteritis and this observation was clearly of practical importance for the interpretation of proximal small intestinal biopsics in children. At Queen Elizabeth Hospital for Children the existence of patchy rather than uniform mucosal abnormality was later shown in biopsy material using a double port modification of the paediatric Crosby capsule, ${ }^{,}$the development of which had been directly inspired by the necropsy study. Postenteritis enteropathy and cow's milk sensitive enteropathy were shown to be often associated with patchy abnormality."

In the autopsy study 'finger-like villi' frequently occurred in the small intestine of neonates, particularly in the ileum, and broader villi occurred more frequently in children aged between five months and five years. In children over the age of five years, finger-like villi were seen along the length of the small intestine. ${ }^{+}$What is the significance of these broader villi? Wright et al" found that in childhood controls compared with adult controls that the epithelial cell transit time in the crypts was $40 \%$ less than in adults. Furthermore the corrected mitotic index was $20 \%$ greater. Thus in view of the apparent reduction in surface area of the small intestine in early childhood as judged by the broader villi found on dissecting microscopy, it would seem that the rate of epithelial turnover is greater in children from the neonatal period into early childhood.

\section{Mucosal immune responses and intestinal morphology}

The reasons for the changing villus shape during ontogeny and in disease are still unclear. A similar 


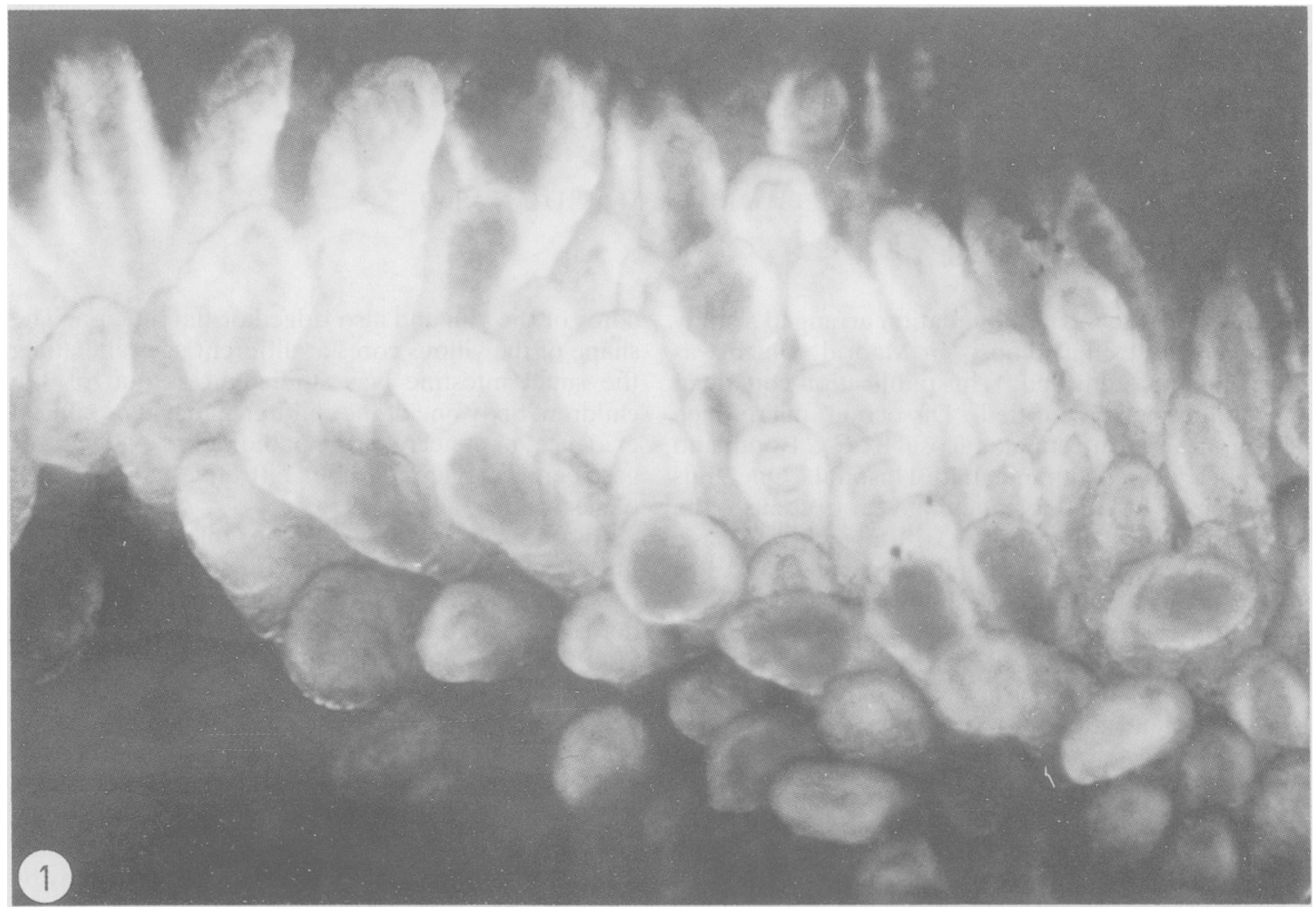

Fig. 1 Dissecting microscope appearances of normal jejunal mucosa in an adult.

change has been described in animals - for example, at birth, in the rat, the villi are 'finger-shaped' but become 'leaf-shaped' after 10 days." Similar changes occur in the long nosed bandicoot. ${ }^{12}$ Gleeson et al ${ }^{13}$ have shown in the rat that if the jejunum is bypassed it changes from normal adult ridges to leaves and that the bypassed ileum changed from adult leaf-like to finger-like villi. This change in villus shape could be the result of direct effects of food and bacteria per se but could also in turn be because of immune reactions to the food or bacteria, as the mucosa in the rat becomes infiltrated with lymphocytes after birth. ${ }^{1+}$ When adult rats are infected with the parasitic worm Nippostrongylus brasiliensis the mucosa becomes inflamed and the villi become shorter and change from leaves to ridges. ${ }^{15}$

Finally, in untreated coeliac discase studied in an adult at necropsy the villi changed from fingers and leaves in the distal gut to short ridges more proximally and finally in the upper gut disappeared with a flat mucosa."Thus there would appear to be a relationship between inflammation in the bowel wall and villus shape. The mild inflammatory response seen in the normal small intestine in response to food or bacteria could be responsible for changing villus shape without pathological consequences. In acute inflammation, however, villus shape could be directly affected by immunological mechanisms, producing adverse effects.

Whatever the reasons for the changes in villus shape during ontogeny in the fetus and after birth it is clear that the most important feature of the small bowel is the constant renewal of villus ephthelial cells by proliferating stem cells in the crypts of Leiberkühn. There are undoubtedly many different factors important in the control of such crypt cell proliferation. These include enteroglucagon, insulin, steroid hormones, epidermal growth factor, prostaglandins and neuropeptides. The changes in crypt cell production seen in inflammation in the bowel, however, most noticeably in coeliac disease, were of particular interest to $\mathrm{C} \mathrm{C}$ Booth. It is well known that the proximal small intestine mucosa in untreated cocliac disease is characterised by a flat mucosa with damaged surface enterocytes, ${ }^{\text {th }}$ accompanied by hypertrophic crypts producing cells 10 times the normal rate." 


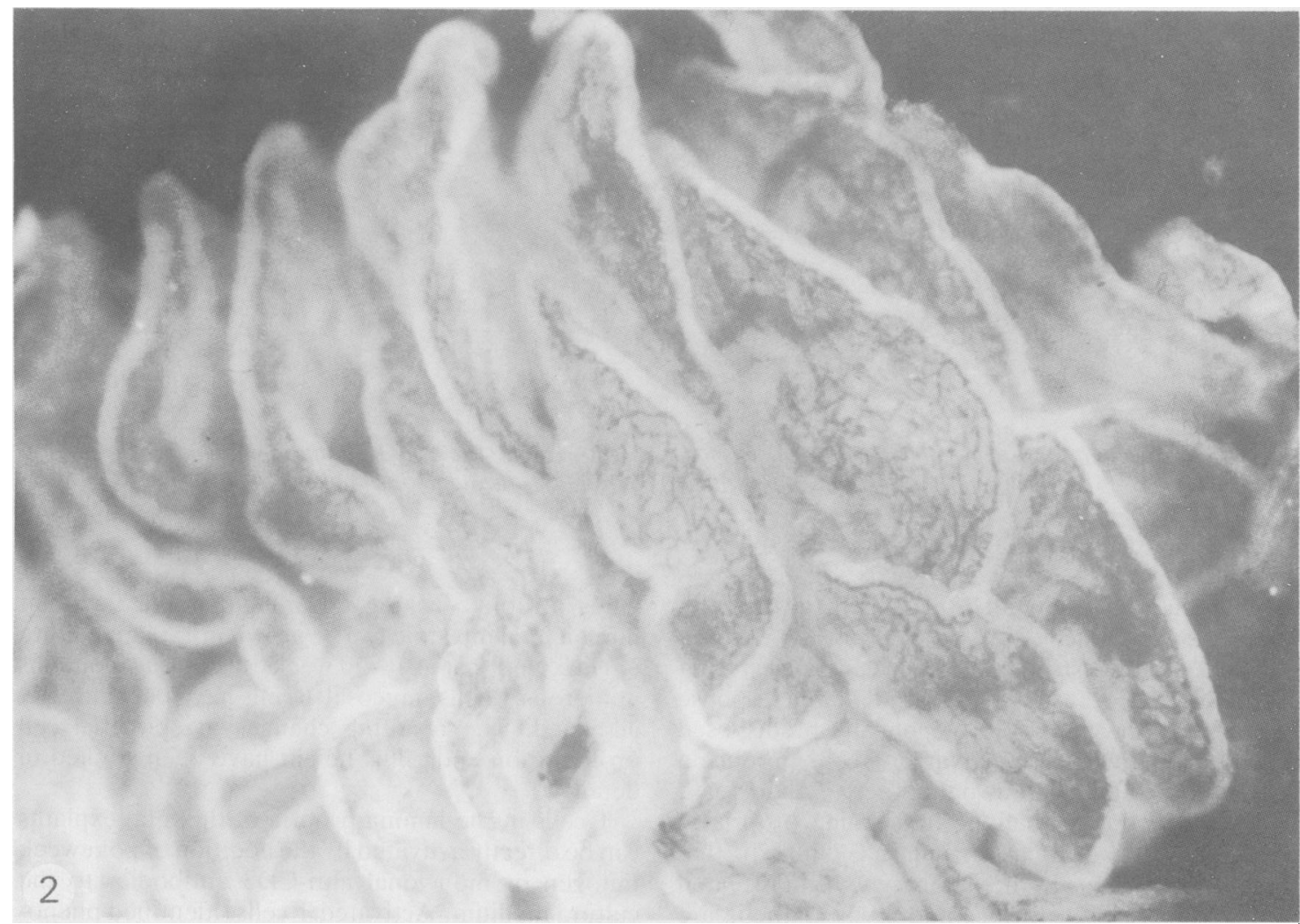

Fig. 2 Dissecting microscope appearances of jejunal mucosa which is histologically normal in a child of one year.

Booth coined the term 'enteropoeisis' to describe epithelial cell production in the crypts, by analogy with haematopoetic system, and termed the proliferating epithelial cells "enteroblasts'." In the same article he also used the words microcytic, normocytic and macrocytic to describe epithelial cells in different conditions. For example, surface enterocytes in coeliac disease would be considered to be microcytic. These descriptive terms failed to catch on but the terms enterocyte and enteroblast are widely used.

In two important articles in 1970, Booth reviewed the structure and function of the enterocyte in coeliac discase. ${ }^{111}$ In these articles he proposed that the primary defect in coeliac disease was damage by gluten to the surface epithelial cells which resulted in increased cell loss from the villus. Crypt hypertrophy and enteroblast hyperplasia were secondary effects in an attempt to replace the surface enterocytes being lost at an increased rate. Implicit in this notion is that some kind of communication must exist between villus epithelial cells and crypt cells, or else how would crypt cells know that there was increased epithelial cell loss? This attractive idea which is widely accepted, has, however, not yet been shown to be correct.

\section{Studies in coeliac disease}

One way to address the question of the generation of the flat mucosa is to investigate changes in mucosal morphology in patients with treated coeliac disease after gluten challenge. Some investigators have shown that within a few hours of challenge there is epithelial cell damage." 211 This would suggest that gluten is toxic to coeliac epithelial cells per se but this hypothesis is not widely accepted. Alternatively, local antibody mediated hypersensitivity may be respon-

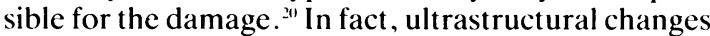
suggestive of immune complex hypersensitivity have been seen in the mucosa of coeliac children shortly after challenge, but no opithelial cell damage was noted."- Because coeliac disease can occur in hypogammaglobulinaemic patients, ${ }^{2 .}$ local immune complex reactions, while producing damage, may be 


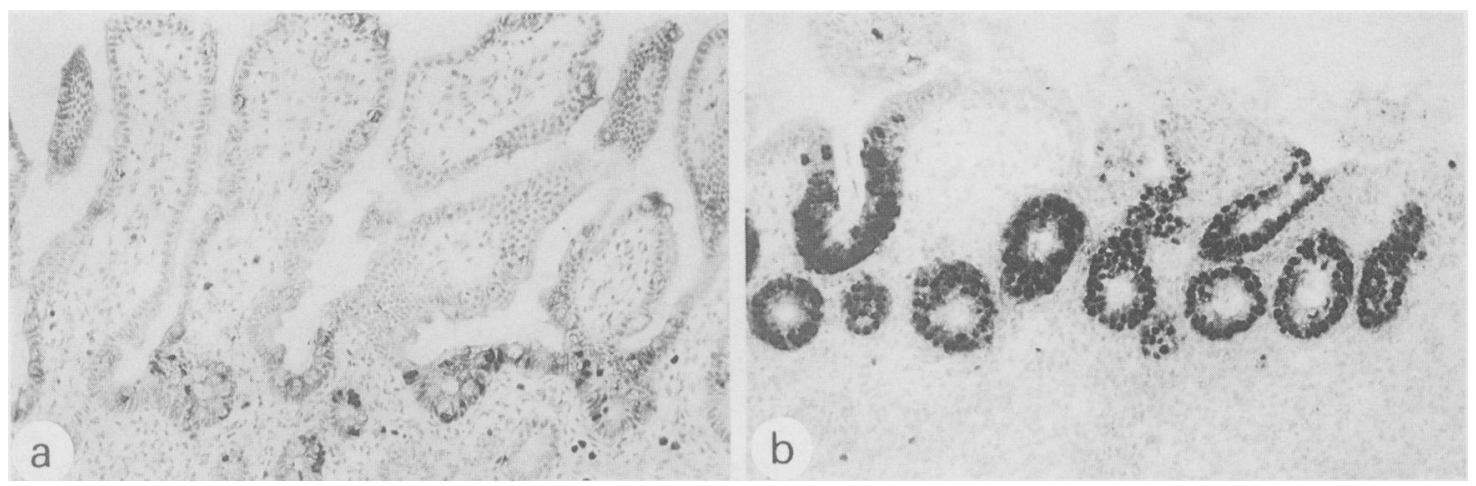

Fig. 3 Frozen sections of fetal small gut from 18 weeks old, fetus after culture for 72 hours stained immunohistochemically with Ki67 (Dako Lid) which stains nuclei of dividing cells. (a) control; (b) after addition of pokeweed mitogen.

epiphenomenal and cannot be primary in the development of the flat mucosa.

There is now strong evidence to suggest that coeliac disease is caused by a T cell-mediated response to gluten in the mucosa of genetically predisposed individuals. How might activated $T$ cells produce a flat mucosa? It is well known that there is an increase in $\mathrm{T}$ cells in the epithelium and lamina propria in untreated coeliac disease, ${ }^{2+}$ but it is unlikely that these directly damage the enterocytes. In untreated coeliac disease both surface and crypt epithelia are infiltrated with lymphocytes but only surface cells and not the crypt enterocytes are damaged..$^{25} \mathrm{It}$ is, in fact, striking that in coeliac disease the enterocytes are normal until the neck of the crypt. As they pass onto the surface they become damaged. In In support of this observation there is firm evidence from study of brush-border hydrolyses that the replacement of mature enterocytes by immature enteroblasts cannot provide an explanation for observed changes in coeliac enterocytes. ${ }^{\text {th }}$

It is also important to appreciate that damaged surface epithelial cells are a feature of a number of conditions other than coeliac disease. These include postenteritis syndrome, cow's milk allergy, intractable diarrhoea of infancy, and transient hypogammaglobulinemia.

\section{T cell mediated enteropathy in foetal human small intestine}

One of the main problems in studying the development of villus atrophy in patients is the ethical and technical considerations in taking multiple biopsies. There is also the problem of sampling error referred to above. One of us (TTM) has recently developed a novel system with which to investigate the genesis of villus atrophy. Taking advantage of the fact that human fetal intestine can be grown in explant culture in vitro, and that at $18-20$ weeks gestation it contains numerous $T$ cells, mucosal $T$ cells have been directly activated. The resulting changes in epithelial cell proliferation and villus height have been studied in detail..$^{24}$

T cells in the lamina propria of the fetal explants can be directly activated by the addition of pokeweek mitogen or monclonal anti-CD3 antibodies to the cultura medium. Activated $T$ cells, identified phenotypically using immunoperoxidase immunochemistry in frozen sections can be seen as early as 12 hours of culture. By 24 hours there is a two to three-fold increase in the number of crypt epithelial cells in the cell cycle compared with freshly isolated tissue,,$"=$ yet villus height remains the same as in controls. Crypt cell proliferation increases dramatically (10-20 fold) over the next few days, and the villi then get shorter (Fig. 3). Despite the change in villous architecture, however, at no time are the surface epithelial cells damaged." Thus in this human fetal model system, T cells can be activated non-specifically in the lamina propria and it can clearly be shown that crypt epithelial cell hyperplasia precedes villus atrophy. In these $T$ cell stimulated organ cultures, surface enerocytes remain normal yet villus atrophy develops. As well as directly showing that activated $T$ cells can affect epithelial cell renewal, these results show that the genesis of the flat mucosa may be the result of changes in crypt length. The usual consequence of crypt cell hyperplasia is crypt hypertrophy. As long as the total mucosal thickness remains the same, crypt hypertrophy must produce an 'apparent' villus at rophy, as by definition the villus starts at the villus/ crypt junction. Lengthening of the crypts to almost full mucosal thickness will produce a flat, mucosa. 
Increased crypt cell production will lead to a faster rate of cell migration across the shortened villi and increased epithelial cell loss. The important question, however, is how to explain the damage to the surface enterocytes found in coeliac disease. As pointed out, however, damaged epithelial cells are not pathognomic of cocliac disease but are found in a variety of small intestinal enteropathies.

It is possible that epithelial cell damage is nonspecific in cocliac disease because of changes in the unstirred water layer and loss of mucus associated with the flat mucosa. In the normal small intestine, the 'finger-like' villi are packed together and enterocytes on the sides of the villi have minimal exposure to luminal contents. When they get near the top of the villi, however, they begin to appear damaged. ${ }^{31}$ In the flat mucosa, as soon as the enterocytes leave the crypts they are exposed to the 'open' lumen. This may lead to non-specific damage.

\section{Conclusion}

The cause of the broadening of villi in infancy and early childhood remains unexplained but may be related to a transient immune reaction to dietary foods and bacteria which in turn may be related to the capacity of $T$ cells in the small intestine to be activated by such dietary factors. Activated $T$ cells have been shown to produce epithelial cell prolifertion with crypt hypertrophy and reduction of villus height in a human fetal organ culture system. This represents a notable advance in our understanding of the development of small intestinal enteropathy.

\section{Academic Department of Paediatric Gastroenterology, Medical College of St Bartholomew's Hospital, London}

\section{References}

I Wolstenholme GEW, Cameron MP. Intestinal biopsy. Ciba Foundation study-group no 14. London: Churchill 1962.

2 Booth CC, Stewart JS, Holmes R, Brackenbury W. Dissecting microscope appearances of intestinal mucosa. Ciba Foundation Study Group no 14. London: Churchill, 1962: p2-19.

3 Walker-Smith JA. Dissecting microscope appearance of small bowel mucosa in childhood. Arch Dis Child 1967; 42: 626-30.

4 Walker-Smith JA. Variation of small intestinal morphology with age. Arch Dis Child 1972; 47: 80-3.

5 Ferguson A. Maxwell JD, KE. Progressive changes in the small intestinal villous pattern with increasing length of gestation. J Pathol 1969; 99: 87.

6 Creamer B, Leppard P. Post-mortem examination of a small intestine in the coeliac syndrome. (iut 1965: 6: 466 .

7 Walker-Smith JA. Uniformity of dissecting microscope appearances in proximal small intestine. Gut 1972; 13: 17-20.

8 Kilby A. Pacdiatric small intestinal biopsy capsule with two parts. Gut 17: 158.

9 Walker-Smith JA. Dissecting microscope appearances of the small intestine in childhood: a post-mortem study. Sydney: MD Thesis University of Sydney, 1970.

10 Wright NA, Watson A, Morley A. Appleton D, Marks J. Cell kinetics in flat (avillus) mucosa of the human small intestine. Gut 1973; 14: 701-10.

11 Baker SJ, Mathan VI, Cherian. The nature of the villi in the small intestine of the rat. Lancet 1963; i: 860.

12 Van Lennep EW. The histology of the mucosa of the small intestine of the long-nosed bandicoot. Acta Anat 1969; 50: 73 .

13 Gleeson MH, Gillen J, Collins J, Dowling RH. Structural and functional changes in rat jejunum and ileum after surgical exclusion from normal intestinal continuity. Gut 1970; 10: 1057.

14 Cerf-Bensussan N, Quaroni A, Kurnick JT, Bhan AK. Intraepithelial lymphocytes modulate la expression by intestinal epithelial cells. J Immunol 1984; 132: 2244-52.

15 Symons LEA. Kinetics of epithelial cells and morphology of villi and crypts in the jejunum of the rat infected by the nematode Nippostrongypus brasiliensis. Gastroenterology 1965; 49: 1.58-68.

16 Padykula HA. Strauss EW, Ladman AJ, Gardner FH. A morphologic and histochemical analysis of the human jejunal epithelium in non tropic sprue. Gastroenterology 1961; 40 735-65.

17 Booth CC. Enteropoesis: structural and functional relationships of the enterocyte. Postgrad Med J 1968; 44: 12-16.

18 Booth CC. An enterocyte in cocliac disease. Br. Med J 1970; 3: 725-31.

19 Booth CC. The enterocyte in coeliac disease. Br. Med J 1970; 4: 14-17.

20) Anand BS. Piris j, Jerrome DW, Offord RE, Truelove $\mathrm{SC}$. The timing of histologic damage following a single challenge with gluten in treated coeliac disease. $Q J$ Med 1981; 197: 83-94.

21 Bramble MG, Zucoloto S, Wright NA, Record CO. Acute gluten challenge in treated adult coeliac disease: a morphometric and enzymatic study. Gut 1985; 26: 169 74.

22 Shiner $M$. Ultrastructure changes in suggestive of immune reactions in the jejunal mucosa of cocliac children following gluten challenge. Gut 1973; 14: 1-12.

23 Webster ADB, Slavin G, Shiner M, Platts-Mills TAE, Asherton GL. Coeliac disease with severe hypogammaglobulinacmia. Gut 1981; 22: 153-7.

24 Selby WS, Janossy G, Bofill M, Jewell DP. Lymphocyte subpopulations in the human small intestine. The findings in normal mucosa and in the mucosa of patients with adult coeliac disease. Clin Exp Immunol 1983; 52: 219-28.

25 Marsh MN, Hinde J. Morphometric analysis of small intestinal mucosa 111 . The quatitation of crypt epithelial 
volumes and lymphoid cell infiltrates with reference to cocliac spure mucosac. Virch Arch Path Anat 1986; 409: 11.

26 Phillips AD, Smith MW, Walker-Smith JA. Selective alteration of brush-border hydrolases in intestinal discases in childhood. Clin Sci 1988; 74: 193-200.

27 Katz AT, Falchuck ZM. Definitive diagnosis of gluten sensitive enteropathy. Use of in vitro culture model. Gastroenterology 1978; 75: 655-670.

28 Kuitunen P. Kosnai I. Savilahti E. Morphometric study of the jejunal mucosa in various childhood enteropathies with special reference to intraepithelial lymphocytes. J Paed Gastro Nutr 1982; 1: 525-31.
29 MacDonald TT, Speneer JM. Evidence that activated mucosal $T$ cells play a role in the pathogensis of enteropathy in human small intestine. $J$ Exp Med 1988: 167: 1341-9.

30) Da Cunha Ferreira R, Richman PI. Wells C. Spencer J. MacDonald TT. Changes in the rate of crypt epithelial cell proliferation and mucosal morphology induced by $\mathrm{T}$ cell mediated response in human small intestine. (Gastroenterology 1989 (In press).

31 Phillips AD, France NE, Walker-Smith JA. The structure of the enterocyte in relation to its position on the villus in childhood: an electron microscopic study. Histopathology 1979; 3: 117-30. 